\title{
Prevalence and type of potential pharmacokinetic drug- drug interactions in old aged psychiatric patients
}

\author{
Gudrun Hefner ${ }^{1,2 *}$, Stefan Unterecker ${ }^{3}$, Nagia Ben-Omar ${ }^{4}$, Margarete Wolf ${ }^{4}$, Tanja Falter ${ }^{2}$, Christoph Hiemke ${ }^{1}$ and Ekkehard Haen ${ }^{4}$ \\ ${ }^{1}$ Department of Psychiatry and Psychotherapy, University Medical Center Mainz, Germany \\ ${ }^{2}$ Institute of Clinical Chemistry and Laboratory Medicine, University Medical Center Mainz, Germany \\ ${ }^{3}$ Department of Psychiatry, Psychosomatics, and Psychotherapy, University Hospital of Würzburg, Germany \\ ${ }^{4}$ Department of Psychiatry and Psychotherapy, University of Regensburg, Germany
}

\begin{abstract}
Purpose: The number of prescribed drugs increases with age, and resulting polypharmacy bears the risk of drug-drug interactions (DDI). We assessed the prevalence and type of cytochrome P450 (CYP) associated pharmacokinetic DDI that were considered as clinically relevant in elderly psychiatric patients under conditions of every day pharmacotherapy.

Methods: For retrospective analysis a large therapeutic drug monitoring (TDM) data base was used. Patients included were elderly in- and outpatients, aged $\geq 65$ years with a psychiatric disorder for whom serum level measurements of a psychotropic drug had been requested. Medication data were examined for co-prescription of clinically relevant CYP inhibitors or inducers and drugs that are substrates of these enzymes (victim drugs).

Results: Data from 1243 patients ( $65.3 \%$ female) with a mean ( \pm standard deviation) age of $73 \pm 6$ years were available for analysis. Mean number of prescribed drugs was $5.3 \pm 3.4$ per patient. Moderate $(n=189,73.8 \%)$ or strong $(n=67,26.2 \%)$ CYP inhibitors or inducers were prescribed in $18.9 \%$ of all patients. Most frequently prescribed CYP inhibitors were duloxetine (CYP2D6 inhibitor, $n=73,31.7 \%)$, melperone (CYP2D6 inhibitor, $n=63,27.4 \%)$ and omeprazole (CYP2C19 inhibitor, $\mathrm{n}=20,8.7 \%$ ). Carbamazepine was the most commonly prescribed CYP inducer (primarily CYP3A4 inducer, $\mathrm{n}=25$, 96.2\%). Taken inhibitory, inducing and substrate properties of combined drugs together, CYP-mediated DDI considered as clinically relevant could be detected in 133 (10.7\%) of included patients.
\end{abstract}

Conclusions: CYP-mediated DDI are common among elderly psychiatric patients. To avoid potentially supra- or sub-therapeutic concentrations of victim drugs, physicians should be more aware of these preventable interactions and adjust the dose.

\section{Introduction}

The potential for drug-drug interactions (DDI) is increasing exponentially [1] with increasing drug intake. Especially in the elderly, polypharmacy [2] increases the risk of DDI [3] and therefore the probability of adverse drug reactions (ADRs) [4,5].

DDI are classified into two main groups. Pharmacodynamic interactions act by potentiation or antagonism at the target structure. Pharmacokinetic DDI occur when a drug alters the absorption, distribution, metabolism, or clearance of another, the victim drug [6].

Several enzymatic systems are involved in pharmacokinetic DDI, most prominent is the cytochrome P450 (CYP) system [7]. Inhibition or induction of CYP metabolism is recognized as most important mechanisms of pharmacokinetic DDI, although DDI related to involvement of CYP isoenzymes constitute only a small proportion of ADRs [8]. Pharmacokinetic DDI are important because they are often predictable and therefore avoidable [6].

Pharmacokinetic DDI may result in serious toxicological serum concentrations or in sub-therapeutic concentration and loss of action of a victim drug if the dosage is not adjusted [9]. The seriousness of a DDI depends on the serum concentration of the victim drug and its therapeutic index [10]. To avoid pharmacokinetic DDI, substrate, inhibitor, and inducer properties for the CYP isoenzymes of all combined drugs must be considered [11].

A growing appreciation for CYP-related DDI resulted in an identification of multiple drugs as CYP substrates, inhibitors or inducers $[9,12]$. Thereby the magnitude of potential drug interactions was often neglected. This has lead to alerts that are clinically unimportant and do not require changes of medications or dose (overalerting) [13]. Therefore, the CYP-inhibitory or -inducing potential of combined drugs must be considered. The Food and Drug Administration (FDA) categorized inhibitors or inducers as strong, moderate or weak based on pharmacokinetic studies. This was published in an updated version on a FDA website for drug development and drug interactions [14]. The last update was in July 2011.

Moderate and strong inhibitors can be regarded as clinically

Correspondence to: Gudrun Hefner, Institute of Clinical Chemistry and Laboratory Medicine, University Medical Center, Langenbeckstrasse 1, 55131 Mainz, Germany, Tel: +49 (0) 6131 17-7092; Fax: +49 (0) 6131 17-6627; E-mail: gudrun.hefner@unimedizin-mainz.de

Key words: elderly, psychiatry, interactions, pharmacokinetics, Cytochrome P450

Received: June 08, 2015; Accepted: July 23, 2015; Published: July 27, 2015 
relevant, since for moderate inhibitors, a more than $50 \%$ decrease of the clearance is defined which leads to an at least twofold increase of drug concentrations in blood.

Most pharmacokinetic DDI of psychotropic drugs occur at the metabolic level involving the CYP enzyme system [15]. Psychotropic DDI give rise to highly variable serum-concentrations of the respective victim drug $[9,10,16]$, leading to ADRs $[17,18]$. Thereby, elderly patients are particularly sensitive to ADRs, especially because of age-related changes in pharmacokinetics and pharmacodynamics $[19,20]$, a higher prevalence of comorbidity [21] and a high rate of drug consumption [2] which increases the risk of drug interactions [3]. For risk minimization due to application of potentially harmful drug combinations, physicians should amongst others consider drug history and prescribe appropriate drugs with a minimum of critical combinations [22] to improve safety and effectiveness of psychopharmacological treatment.

Until recently, studies on the prevalence and relevance of DDI regarding the gradual impact on the metabolism of a victim drug in a naturalistic clinical setting are lacking. This study examined the prevalence of combinations of clinically relevant CYP enzyme inhibitors or inducers, considered as "strong" or "moderate" based on a pharmacokinetic classification [14], with drugs that are preferred substrates for these enzymes (victim drugs) in elderly psychiatric patients. It was hypothesized for old aged psychiatric patients that the number of CYP associated DDI increases with increasing number of prescribed drugs. Moreover, it was investigated which CYP enzymes and drugs are primarily affected by pharmacokinetic DDI in old aged psychiatric patients.

\section{Methods}

\section{Study design}

The present retrospective analysis used information from a large therapeutic drug monitoring (TDM) database. It originated from 2999 TDM requests raised in the TDM laboratories of the Departments of Psychiatry and Psychotherapy at the Universities of Mainz and Regensburg (Germany) between 1998 and 2014. These laboratories receive blood samples for TDM of psychoactive drugs from multiple psychiatric hospitals in Germany. Overall, a data set from 922 TDM requests were obtained from Regensburg [23] and data from 2077 TDM requests were obtained from the University Medical Center of Mainz. All included patients were aged at least 65 years and had a psychiatric diagnosis according to International classification of Mental and Behavioural Disorders, 10th Revision (ICD-10). Databases included person-specific information given on the TDM request forms [9]. Retrospective analysis of clinical data for this study was in accordance with regulations given by the local ethics committee of the Ärztekammer Rheinland-Pfalz.

\section{Patients}

Age, gender, psychiatric diagnosis and medication were recorded for analysis. Applied medications at the day of blood-withdrawal were considered. The total number of prescribed medications was calculated, excluding dietary supplements, as vitamins and mineral nutrients. Each patient was included for analysis only once. When multiple serum level measurements were requested for the same patient, only the first request was considered. Thus, a higher prevalence rate of pharmacokinetic DDI was expected at the first request, as the reported TDM result includes dose and medication recommendation (DDI check) by the laboratory. Patients were excluded when data about medication or age were insufficient or when the patient identification number was not available.

\section{Drug combinations}

Medication data were examined for co-prescription of CYP inhibitors or inducers and corresponding substrates (victim drugs). CYP inhibitors were defined "strong" or "moderate" in accordance with a classification proposed by the FDA [14]. CYP inhibitors identified as "strong" ( $>5$-fold increase in area under the plasma concentration-time curve (AUC) or $>80 \%$ decrease in clearance) or "moderate" ( $>2$-fold but $<5$-fold increase in the AUC or $50-80 \%$ decrease in clearance) and CYP inducers defined as "strong" ( $\geq 80 \%$ decrease in AUC) or "moderate" (50-80\% decrease in AUC) were considered for analysis. In addition to this information and based on reported literature, melperone [24] and levomepromazine [25] were designated as moderate CYP2D6 inhibitors and perazine as a strong CYP1A2 inhibitor [26-28].

CYP substrate properties were considered to define victim drugs in accordance with the Consensus Guidelines for TDM in Psychiatry of the Arbeitsgemeinschaft für Neuropsychopharmakologie und Pharmakopsychiatrie (AGNP) [9] who defined victim drugs for distinct CYP enzymes. For non-psychotropic victim drugs, CYP substrate properties were identified by the CYP450 Drug Interaction Table of Indiana University [29].

\section{Statistical analysis}

Descriptive statistics of patients' data were presented as mean values \pm standard deviations (mean $\pm \mathrm{SD}$ ). For comparisons between gender and patients with and without a detected DDI, the MannWhitney $U$ test was used, as the variables were not normally distributed. To evaluate a difference between two nominal variables (gender and DDI), the chi square test for independence was used. Statistical analysis was carried out using IBM ${ }^{\circ}$ SPSS Statistics version 21.0 (IBM GmbH, Ehningen, Germany). A 95\% confidence interval (CI) was applied and a p-value $<0.05$ was considered statistically significant.

\section{Results}

In total, data from 1243 patients (65.3\% female) were available. Patients' mean age was $73 \pm 6$ years (range 65-101 years). Data on diagnosis was given for 809 patients $(65.1 \%)$. Most frequent diagnoses (ICD-10) were a recurrent depressive disorder (F33) with $32.9 \%$, a depressive episode (F32) with $21.7 \%$, schizophrenia (F20) with $8.9 \%$, Alzheimer's dementia (F00) with $5.2 \%$ and a bipolar affective disorder (F31) with $4.7 \%$. Mean number of prescribed drugs was $5.3 \pm 3.4$ (range $1-25)$. As 156 elderly patients (12.6\%) were under monotherapy, DDI were analyzed for 1087 cases.

The number of prescribed drugs differed significantly $(U(1243)=108087.5 ; \mathrm{p}<0.001 ;$ CI $95 \%)$ in patients with and without a detected DDI $(7.9 \pm 3.8$ vs. $5.0 \pm 3.3)$, but age was similar $(72.2 \pm$ 5.7 vs. $73.6 \pm 6.3$ ) in both groups. With increasing number of drugs the occurrence of DDI increased (Figure 1). With regard to gender, there was no significant difference $(U(1243)=175193.5 ; \mathrm{p}>0.05$; CI $95 \%$ ) concerning number of prescribed drugs. Mean number of drugs was similar in females $(5.3 \pm 3.4)$ and males $(5.3 \pm 3.5)$. Nevertheless, significantly $\left(\chi^{2}=5.25 ; \mathrm{p}<0.05\right.$; CI $\left.95 \%\right)$ more CYP-mediated DDI were detected in male patients (13.5\%), compared with female patients (9.2\%). The most frequently affected CYP enzyme was CYP2D6, followed by CYP3A4 and CYP2C19 (Figure 2). In total, 256 CYP inhibitors and inducers were prescribed in 235 (18.9\%) of the 1243 

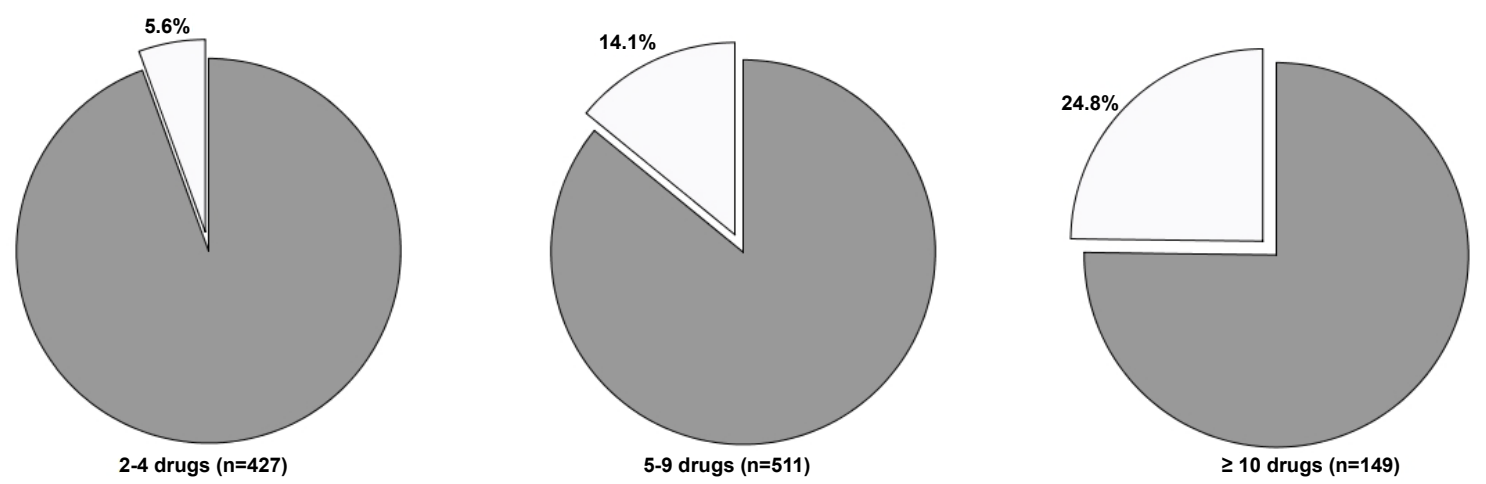

CYP450 drug-drug interaction

$\square$ Yes

$\square$ No

Figure 1. Number of patients (\%) with potential clinically relevant cytochrome P450 (CYP)-mediated drug-drug interactions as a function of the number of drug-prescriptions, identified in the study population of 1243 psychiatric patients. 156 patients were under monotherapy.

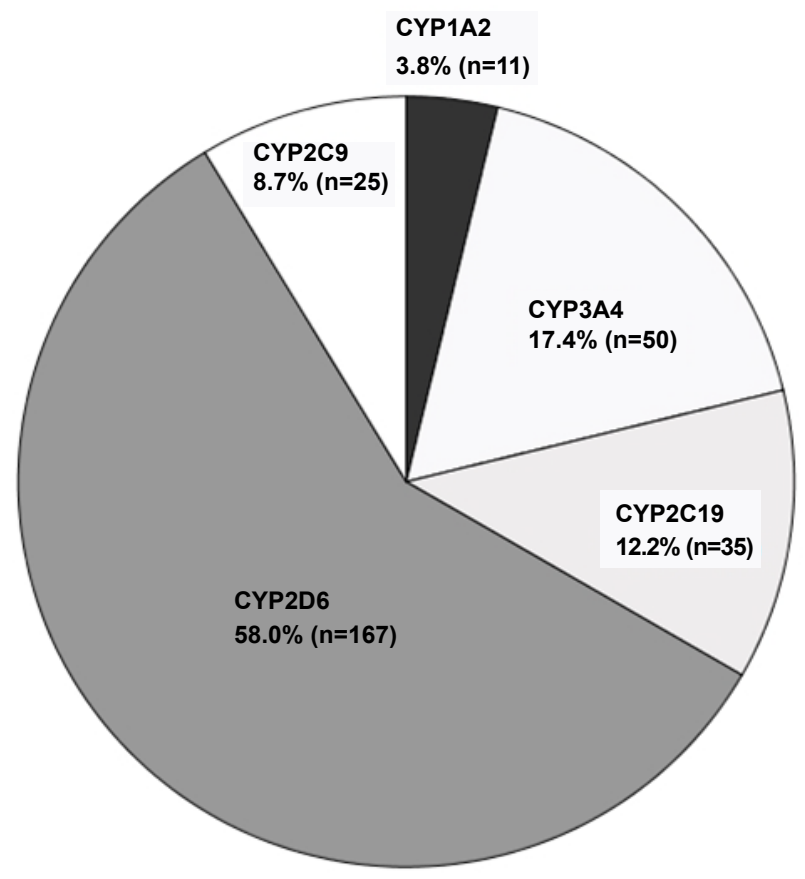

Figure 2. Cytochrome P450 (CYP) isoforms $(n=288)$ that were affected by comedication with a respective CYP inducer or inhibitor $(n=256)$, identified in 235 of 1243 old aged patients included for this analysis.

patients, of which $73.8 \%$ were categorized as moderate $(\mathrm{n}=189)$ and $26.2 \%$ as strong $(n=67)$ CYP inhibitors and inducers. CYP inhibitors were prescribed to $212(17.1 \%$, Table 1$)$ and CYP inducers to $26(2.1 \%)$ of the elderly patients (Table 1 ). In three patients, the CYP inducer carbamazepine was combined with one of the three CYP inhibitors melperone, levomepromazine or omeprazole. Mean number of prescribed CYP inhibitors and inducers was $0.2 \pm 0.5$ (range 0-3).

The most frequently prescribed CYP inhibitors (Table 1) were duloxetine (moderate CYP2D6 inhibitor, $\mathrm{n}=73,31.7 \%$ ), melperone (moderate CYP2D6 inhibitor, $\mathrm{n}=63,27.4 \%$ ), omeprazole (strong CYP2C19 inhibitor, $\mathrm{n}=20,8.7 \%$ ), bupropion (strong CYP2D6 inhibitor, $\mathrm{n}=18,7.8 \%$ ) and verapamil (moderate CYP3A inhibitor, $\mathrm{n}=17,7.4 \%$ ). Combinations with victim drugs were detected in 40 $50 \%$ of the patients who took bupropion, duloxetine, omeprazole or
Table 1. Clinically relevant inducers and inhibitors of cytochrome P450 (CYP) enzymes that were prescribed and identified in 1243 elderly patients. Overall, $212(17.1 \%)$ and 26 (2.1\%) patients received strong or moderate CYP inducers or inhibitors, respectively.

\begin{tabular}{|l|c|c|c|c|c|}
\hline & $\begin{array}{c}\text { Affected CYP- } \\
\text { isoenzyme }\end{array}$ & Strength* & $\begin{array}{c}\text { No of patients } \\
\text { [n Total; } \%\end{array}$ & $\begin{array}{c}\text { DDI } \\
\text { No/Yes }\end{array}$ & DDI [\%] \\
\hline Inhibitor & 2D6 & Strong & $18(7.8)$ & $10 / 8$ & 44.4 \\
\hline Bupropion & $1 \mathrm{~A} 2$ & Strong & $2(0.9)$ & $0 / 2$ & 100.0 \\
\hline Ciprofloxacin & $3 \mathrm{~A} 4$ & Moderate & & & \\
\hline Clarithromycin & $3 \mathrm{~A} 4$ & Strong & $2(0.9)$ & $0 / 2$ & 100.0 \\
\hline Diltiazem & $3 \mathrm{~A} 4$ & Moderate & $1(0.4)$ & $1 / 0$ & 0 \\
\hline Duloxetine & $2 \mathrm{D} 6$ & Moderate & $73(31.7)$ & $42 / 31$ & 42.5 \\
\hline Esomeprazole & $2 \mathrm{C} 19$ & Moderate & $8(3.5)$ & $2 / 6$ & 75.0 \\
\hline Fluvoxamine & $1 \mathrm{~A} 2$ & Strong & $5(2.2)$ & $1 / 4$ & 80.0 \\
\hline & $2 \mathrm{C} 19$ & Strong & & & \\
\hline Imatinib & $3 \mathrm{~A} 4$ & Moderate & $1(0.4)$ & $0 / 1$ & 100.0 \\
\hline Levomepromazine & $2 \mathrm{D} 6$ & Moderate & $5(2.2)$ & $0 / 5$ & 100.0 \\
\hline Melperone & $2 \mathrm{D} 6$ & Moderate & $63(27.4)$ & $20 / 43$ & 68.3 \\
\hline Moclobemide & $2 \mathrm{C} 19$ & Moderate & $1(0.4)$ & $0 / 1$ & 100.0 \\
\hline Nefazodone & $3 \mathrm{~A} 4$ & Strong & $1(0.4)$ & $1 / 0$ & 0 \\
\hline Omeprazole & $2 \mathrm{C} 19$ & Moderate & $20(8.7)$ & $10 / 10$ & 50.0 \\
\hline Paroxetine & $2 \mathrm{D} 6$ & Strong & $8(3.5)$ & $5 / 3$ & 37.5 \\
\hline Perazine & $1 \mathrm{~A} 2$ & Strong & $4(1.7)$ & $4 / 0$ & 0 \\
\hline Ticlopidine & $2 \mathrm{C} 19$ & Strong & $1(0.4)$ & $0 / 1$ & 100.0 \\
\hline Verapamil & $3 \mathrm{~A} 4$ & Moderate & $17(7.4)$ & $9 / 8$ & 47.1 \\
\hline Total & & & $230(100)$ & & \\
\hline Inducer & $3 \mathrm{~A} 4$ & Strong & $25(96.2)$ & $11 / 14$ & 56.0 \\
\hline Carbamazepine & $2 \mathrm{C} 9$ & Moderate & & & \\
\hline St. John's wort & $3 \mathrm{~A} 4$ & Strong & $1(3.8)$ & $1 / 0$ & 0 \\
\hline Total & & & $26(100)$ & & \\
\hline & & & & \\
\hline
\end{tabular}

*CYP inducers or inhibitors were classified as "strong" or "moderate" as specified by the U.S. Food and Drug Administration [14].

DDI Drug-Drug Interaction

verapamil. A higher rate of $68.3 \%$ was found for patients who received melperone (Table 1). Therefore, melperone was the most frequently involved CYP inhibitor concerning a DDI.

Carbamazepine was the most frequently prescribed CYP inducer (Table 1) found for $25(96.2 \%)$ of the 26 prescribed CYP inducers, St. 
John's wort was prescribed once $(n=1,3.8 \%)$. Carbamazepine is graded as a strong CYP3A inducer and moderate CYP2C9 inducer, St. John's wort as a strong CYP3A inducer. Combinations with victim drugs were detected for $56 \%$ of the patients who took carbamazepine (Table 1 ).

Combinations of CYP inhibitors or inducers and victim drugs were detected in $133(10.7 \%)$ of the 1243 elderly patients. Overall, 185 victim-drugs could be identified (Table 2 ). The most frequently detected victim drugs were venlafaxine $(\mathrm{n}=34,18.4 \%)$, risperidone $(\mathrm{n}=26,14.1 \%)$, aripiprazole $(\mathrm{n}=13,7.0 \%)$, propranolol $(\mathrm{n}=11,5.9 \%)$ and metoprolol $(\mathrm{n}=10,5.4 \%)$. All these victim drugs are metabolized

Table 2. Substrates of cytochrome P450 (CYP) enzymes identified as victim-drugs $(n=185)$ that were combined with a moderate or strong CYP inducer or inhibitor in the study population. Values given are absolute and relative (\%) number of cases identified in a sample of 1243 elderly psychiatric patients.

\begin{tabular}{|c|c|c|}
\hline Victim-drug & $\begin{array}{c}\text { Major CYP-isoenzymes involved in } \\
\text { the drugs' metabolism* }\end{array}$ & Number of cases \\
\hline Amitriptyline & 2C19, 2D6 & $6(3.2)$ \\
\hline Amlodipine & $3 \mathrm{~A} 4$ & $5(2.7)$ \\
\hline Aripiprazole & 2D6, 3A4 & $13(7.0)$ \\
\hline Carvedilol & 2D6 & $3(1.6)$ \\
\hline Citalopram & $2 \mathrm{C} 19$ & $6(3.2)$ \\
\hline Clonidine & 2D6 & $1(0.5)$ \\
\hline Clozapine & $1 \mathrm{~A} 2,2 \mathrm{C} 19$ & $3(1.6)$ \\
\hline Diclofenac & $2 \mathrm{C} 9$ & $2(1.1)$ \\
\hline Donepezil & 2D6 & $8(4.3)$ \\
\hline Doxepin & $2 \mathrm{C} 9,2 \mathrm{C} 19,2 \mathrm{D} 6$ & $1(0.5)$ \\
\hline Escitalopram & $2 \mathrm{C} 19$ & $1(0.5)$ \\
\hline Flupentixol & 2D6 & $1(0.5)$ \\
\hline Haloperidol & $3 \mathrm{~A} 4$ & $3(1.6)$ \\
\hline Hydrocortisone & $3 \mathrm{~A} 4$ & $1(0.5)$ \\
\hline Imipramine & $1 \mathrm{~A} 2,2 \mathrm{C} 19,2 \mathrm{D} 6$ & $1(0.5)$ \\
\hline Metoclopramide & 2D6 & $8(4.3)$ \\
\hline Metoprolol & 2D6 & $10(5.4)$ \\
\hline Nateglinide & $3 \mathrm{~A} 4,2 \mathrm{C} 9$ & $1(0.5)$ \\
\hline Nebivolol & 2D6 & $1(0.5)$ \\
\hline Nifedipine & $3 \mathrm{~A} 4$ & $1(0.5)$ \\
\hline Nitrendipine & $3 \mathrm{~A} 4$ & $1(0.5)$ \\
\hline Nortriptyline & 2D6 & $1(0.5)$ \\
\hline Oxycodone & 2D6 & $3(1.6)$ \\
\hline Pravastatin & $3 \mathrm{~A} 4$ & $1(0.5)$ \\
\hline Promethazine & 2D6 & $6(3.2)$ \\
\hline Propranolol & 1A2, 2C19, 2D6, 3A4 & $11(5.9)$ \\
\hline Quetiapine & $3 \mathrm{~A} 4$ & $5(2.7)$ \\
\hline Risperidone & 2D6 & $26(14.1)$ \\
\hline Sertraline & 2B6, 2C19 & $2(1.1)$ \\
\hline Simvastatin & $3 \mathrm{~A} 4$ & $2(1.1)$ \\
\hline Temazepam & $2 \mathrm{C} 19$ & $3(1.6)$ \\
\hline Timolol & 2D6 & $1(0.5)$ \\
\hline Tramadol & 2D6 & $1(0.5)$ \\
\hline Trazodone & $3 \mathrm{~A} 4$ & $1(0.5)$ \\
\hline Trimipramine & 2C19, 2D6 & $4(2.2)$ \\
\hline Venlafaxine & 2C19, 2D6 & $34(18.4)$ \\
\hline Zolpidem & $3 \mathrm{~A} 4$ & $2(1.1)$ \\
\hline Zopiclone & $3 \mathrm{~A} 4$ & $5(2.7)$ \\
\hline Total & & $185(100)$ \\
\hline
\end{tabular}

*CYP substrate properties were considered as specified by the AGNP (Arbeitsgemeinschaft für Neuropsychopharmakologie und Pharmakopsychiatrie) expert group for therapeutic drug monitoring in psychiatry [9] and by experts of the Indiana University [29].
Table 3. Most frequent ( $\mathrm{n} \geq 3$ ) pharmacokinetic drug-drug interactions (DDI) because of combining moderate or strong cytochrome P450 (CYP) inducers or inhibitors with victim drugs. Overall, 185 critical combinations were detected in $133(10.7 \%)$ of the 1243 elderly patients of this study. Values are given as absolute and relative (\%) number of cases.

\begin{tabular}{|l|l|c|}
\hline & $\begin{array}{l}\text { DDI } \\
\text { victim drug + CYP inducer or inhibitor }\end{array}$ & Number of cases \\
\hline 1 & Venlafaxine + Melperone & $21(11.4)$ \\
\hline 2 & Risperidone + Melperone & $13(7.0)$ \\
\hline 3 & Risperidone + Duloxetine & $8(4.3)$ \\
\hline 4 & Propranolol + Duloxetine & $7(3.8)$ \\
\hline 5 & Metoprolol + Melperone & $6(3.2)$ \\
\hline 6 & Aripiprazole + Melperone & $5(2.7)$ \\
\hline 7 & Citalopram + Omeprazole & $5(2.7)$ \\
\hline 8 & Metoclopramide + Melperone & $5(2.7)$ \\
\hline 9 & Venlafaxine + Omeprazole & $5(2.7)$ \\
\hline 10 & Aripiprazole + Duloxetine & $4(2.2)$ \\
\hline 11 & Donepezil + Melperone & $4(2.2)$ \\
\hline 12 & Metoprolol + Duloxetine & $4(2.2)$ \\
\hline 13 & Risperidone + Levomepromazine & $4(2.2)$ \\
\hline 14 & Amlodipine + Carbamazepine & $3(1.6)$ \\
\hline 15 & Quetiapine + Verapamil & $3(1.6)$ \\
\hline 16 & Venlafaxine + Bupropion & $3(1.6)$ \\
\hline 17 & Venlafaxine + Esomeprazole & $3(1.6)$ \\
\hline & Total number of DDI & $185(100)$ \\
\hline & & \\
\hline
\end{tabular}

by CYP2D6. Aripiprazole also is metabolized by CYP3A4, propranolol also by CYP1A2, 2C19 and CYP3A and venlafaxine also by CYP2C19 (Table 2). Individual DDI that were observed in at least 3 cases are listed in Table 3. Most frequent were combinations of venlafaxine or risperidone with melperone which amounted to $18.4 \%$ of all observed interaction cases.

\section{Discussion}

This retrospective, naturalistic analysis of data obtained from elderly patients $\geq 65$ years revealed that the prevalence of CYPmediated pharmacokinetic DDI is considerably high in a psychiatric setting (10.7\%). In particular, $19 \%$ of elderly psychiatric patients received a CYP inhibitor or inducer.

A strength of this study was that, to avoid over-alerting [30], only clinically relevant CYP-mediated DDI were considered for analysis. Clinically relevant meant that only "strong" or "moderate" CYP inhibitors or inducers [14] were considered. In this study, a high proportion of ingested CYP inhibitors or inducers were listed as strong (26.2\%) or as moderate $(73.8 \%)$ by the FDA [14]. We chose three sources of CYP inhibitor, inducer and substrate properties of a drug $[9,14,29]$ because they were comprehensive and amongst others based on clinical data. It is concluded that, with this selection-method, an overestimating of the prevalence-rate of CYP-mediated DDI could be avoided.

The comparison of the results in this study with results of other studies [17,31-33] is complicated by the fact that these studies did not consider of the intensity of CYP inhibition or induction. Some studies even used clinical decision support systems to detect CYP-mediated DDI. These systems may help to avoid critical drug combinations, but they tend to produce a large number of irrelevant alerts, in turn leading to over-alerting and causing alert fatigue $[13,30]$. Finally, different patients' inclusion criteria and study-settings complicated comparison 
of results reported in the literature with results of this study. Thus, the following comparisons have to be judged with caution.

In this study, CYP inhibitors were prescribed to $17.1 \%$ of the elderly patients, most frequently duloxetine and melperone. Some studies $[24,34]$ identified melperone as clinically relevant CYP2D6 inhibitor, however, the drug was often neglected in other studies [17,31-33]. As melperone is not approved in the United States, this may explain why the drug is not in the FDA interaction table [14]. It should, however, be considered as a moderate CYP2D6 inhibitor in lists of CYP inhibitors, as melperone is a frequently used drug in Europe.

It is also remarkable that in particular fluoxetine was not prescribed in any of the elderly patients. Furthermore, paroxetine was only prescribed in 8 patients. This may be due to the long and well known CYP2D6-inhibitory properties of these drugs [35]. Therefore, prescription could have been avoided by the physician in these elderly patients. On the other hand, the CYP inhibitory potential of bupropion, duloxetine or melperone and for internistic drugs like omeprazole may be underestimated. In particular, the CYP inhibitory potential of melperone seems likely to be less well known, as a higher rate of DDI (68.3\%) could be detected in those patients who took melperone, compared with other CYP inhibitors (40-50\%).

As the number of detected CYP inducers was much lower, compared with CYP inhibitors [14], the lower prevalence rate in prescribing inducers $(2.1 \%$ vs. $17.2 \%)$ was expected. The long-established moodstabilizer carbamazepine [36] was the most frequently prescribed CYP inducer in this study. As DDIs were detected in $56 \%$ of the patients who took carbamazepine, physicians should consider the CYP inducing potential of carbamazepine, and, if necessary, switch to an alternative mood-stabilizer without CYP inducing potential.

CYP-enzyme inhibitors and inducers were prescribed in this study in 235 (18.9\%) of our patients. The number of pharmacokinetic DDI was notably smaller, i.e. $10.7 \%$, since DDI require combinations with victim drugs.

In our sample, $12.6 \%$ of the patients were under monotherapy and therefore no CYP-mediated DDI was possible. We included those patients to obtain the overall, real-life prevalence rate of CYP-mediated DDI in the psychiatric setting.

Consistently, Preskorn et al. [35] examined a prevalence rate of CYP-mediated DDI of $11 \%$ in veterans affairs who had a prescription for an antidepressant in the preceeding year and a current prescription for at least one systemically active drug. Secondly, Adson et al. [32] examined DDI in $14 \%$ of psychiatric patients (17-84 years) seen on a consultative psychiatry service. Contradictory, Guo et al. [17] analyzed from claims data for adult patients with a diagnosis of schizophrenia a prevalence rate of $23 \%$ for CYP-mediated DDI. The high prevalence rate could be explained by the fact that other methods of CYP inhibitor, inducer and substrate grouping and selection were chosen. E.g. sertraline and haloperidol were defined as CYP2D6 inhibitor in the study by Guo et al. [17], but not in the present study.

In this study, the most frequently CYP-isoform that was affected was CYP2D6, in accordance with previous studies $[17,18]$. As some psychotropic drugs, e.g. duloxetine, fluoxetine, paroxetine, melperone and bupropion inhibit CYP2D6 [9,24,35], the major role of CYP2D6 was expectable for the psychiatric setting.

Referring to the previous result, the most frequently detected victim drugs were the CYP2D6 substrates venlafaxine and risperidone.
In accordance, Guo et al. [17] detected that patients with diagnosis of schizophrenia who took the antipsychotic risperidone were most likely to be exposed to an interaction, compared with other psychotropic drugs.

In accordance with a previous study [31], our patients with a detected DDI received significantly more drugs $(\mathrm{p}<0.001)$ than patients without a detected DDI $(7.9 \pm 3.8$ vs. $5.0 \pm 3.3)$. In this study, $5.6 \%$ of the patients who received $2-4$ drugs, $14.1 \%$ of the patients who received 5-9 drugs and $24.8 \%$ who received $\geq 10$ drugs developed a CYP-mediated pharmacokinetic DDI. Doan et al. [33] detected in community hospitalized patients $\geq 65$ years receiving five or more drugs a much higher probability of at least one CYP-mediated DDI, with 50\% for persons taking 5-9 drugs and 81\% taking 10-14 drugs. Amongst others, this could be explained by the fact that the medication profiles of these patients were analyzed with a multidrug cytochromespecific software program that had another selection of CYP inhibitors, inducers and substrates.

A significant gender-difference concerning CYP-mediated DDI was detected in male patients (13.5\%), compared with female patients (9.2\%). Other studies investigated a higher risk for female patients $[8,17]$, but the mean number of drugs in the gender groups was not considered. After adjusting for the number of drugs dispensed, Doan et al. [33] found no gender differences in the risk of potential CYPmediated DDI. Since the mean number of administered drugs in the present study was similar in females $(5.3 \pm 3.4)$ and males $(5.3 \pm 3.5)$, the increased risk for a CYP-mediated DDI may be simply explained by the fact that different kind of drug combinations were preferably prescribed for females compared with males.

It has to be mentioned that this study only considered pharmacokinetic DDI related to the CYP450 system. Other pharmacokinetic DDI were not considered for this analysis. As an example pharmacokinetic DDI between lithium and non-steroidal anti-inflammatory drugs $[5,37]$ and pharmacokinetic DDI related to the p-glycoprotein transporter or including the uridine 5-diphosphate glucuronosyltransferases were not considered. Furthermore, as we only analyzed pharmacokinetic interactions between two drugs, smoking status was not considered. Therefore, a much greater overall prevalence rate must be considered for pharmacokinetic DDI in the psychiatric setting.

In addition, it has to be mentioned that some augmentation strategies, for example combination therapy with fluvoxamine and clozapine, are intentional therapeutic DDI [38]. In this study, two patients received a combination therapy with fluvoxamine and clozapine. Furthermore, potentially hazardous drug combinations can be used beneficially if appropriate precautions, e.g. dose adjustment, are occasioned [34]. TDM can help to adapt the serum concentration of a victim drug within the therapeutic reference range [9]. This study has not considered the doses, serum levels and the therapeutic indices of the victim drugs and therefore dose-dependent toxicity. Thus, the clinical relevance of the CYP-mediated DDI remains questionable.

Concerning the clinical relevance of our findings, a considerable number of drug-combinations were identified as high risk combinations. This was suggested, since the combination of these drugs reportedly leads to clinical relevant increase or decrease of drug serum concentration of the victim drug due to the proven high inhibitory or inducing potential of combined drugs [14]. Serum concentrations of victim drugs would have been most informative to evaluate the magnitude of DDI effects. Blood level measurements, however, were 
done only for some psychotropic drugs. For most drugs, however, such data were not available, especially for non-psychiatric medications. Therefore, we referred to data in the literature and included Table 4 showing clinically relevant DDIs reported by other investigators [24,34,39-58]. Since drug combinations of Table 4 were similar to the combinations observed by us, we assumed clinical relevance for our findings.

This study had several limitations that need to be considered. Since included patients were selected from a TDM database, a selection bias may be assumed. Patients may not be representative for the "average" patient in a standard psychiatric setting. However, according to the AGNP guidelines for TDM in psychiatry [9], age $\geq 65$ years is an indication to use TDM. Moreover, a number of indications such as combination treatment with a drug known for its interaction potential or pharmacokinetic comorbidities are specific indications to use TDM. In accordance with this guideline recommendation TDM is highly recommended for elderly psychiatric patients in the participating centers. Patients of this study are therefore regarded as representative for elderly psychiatrically ill patients. This view is supported by the finding that the mean number of drugs of the selected patient sample and the gender distribution was similar to that of a previous study on geriatric psychiatric patients [59].

In addition, this study relies on retrospective data which has the limitation that information on medication may be assumed less reliable than in case of a prospective study. On the other hand, prospective studies may not reflect every day practice of psychopharmacotherapy, since supervision of patients and treating physicians may lead to reduction of the number of combined drugs.

\section{Conclusions}

From our findings it may be concluded that the prevalence of CYP-mediated pharmacokinetic drug interactions is high in old aged psychiatric patients. This confirmed our expectation that elderly patients frequently receive strong or moderate CYP inhibitors and to a lesser extent CYP inducers that may give rise to drug interactions when interfering drugs are combined with victim drugs.

\section{Clinical implications}

The results of our study provide implications for the practice of health care especially for old aged patients. CYP related pharmacokinetic drug interactions are frequent in this group. Therefore, especially elderly patients require individualized pharmacotherapy with a comprehensive geriatric assessment, limiting the number of drugs prescribed for an elderly patient as few as is necessary and reviewing the use of drugs regularly [6].

Since CYP mediated drug interactions may lead to severe ADRs [34] and since most of these adverse reactions are considered as preventable medication errors, physicians have to be aware about this risk when prescribing combinations of drugs. Thus, efficacy and safety of psychopharmacotherapy could be improved [60]. CYP inhibitor and inducer properties of drugs must be an element of medication management when more than a single drug is given to a patient. Computer programs can be helpful to control of medications for potential DDIs [30]. Available programs, however, are often incomplete, because of the multiple possible drug combinations [30]. Moreover, computerized alerts are often not meaningful [13]. Regarding CYP inhibiting properties, the physician should pay special attention to CYP2D6 inhibitors. Overall, whenever a drug like melperone, duloxetine or carbamazepine with strong or moderate CYP inhibiting or inducing properties (Table 1) is identified in the medication, the treating physician must check if victim drugs are also present (Table 2). Such combinations should be avoided for safety reasons. If an alternative, non-interacting drug is not available and the critical combination needed for therapy, monitoring of drug concentrations can be helpful to adapt the dosage of the victim drug [9]. If therapeutic drug monitoring guided dose adaptation is not available for the victim drug, careful clinical supervision is mandatory. Using such strategies for drug management and increased awareness of clinically relevant drug interactions will improve the efficacy and safety of pharmacotherapy.

\section{Compliance with ethical standards}

\section{Disclosure of potential conflicts of interest}

Christoph Hiemke has received speaker's or consultancy fees from Pfizer Deutschland GmbH, Janssen-Cilag $\mathrm{GmbH}$ and Servier Deutschland $\mathrm{GmbH}$, outside the submitted work. He reports no conflict of interest with this publication. Ekkehard Haen reports personal fees from Pfizer Deutschland GmbH, Servier Deutschland GmbH, Novartis Pharma GmbH, and Johnson\&Johnson GmbH, outside the submitted work. He reports no conflict of interest with this publication. Gudrun Hefner has received speaker's fee from Servier Deutschland GmbH. She reports no conflict of interest with this publication. All other

Table 4. Pharmacokinetic drug-drug interactions reported in the literature for medications with moderate or strong inducers or inhibitors of cytochrome P450 (CYP) enzymes combined with victim drugs.

\begin{tabular}{|c|c|c|c|}
\hline \multicolumn{2}{|c|}{ CYP inducer/ inhibitor + distinct victim drug } & \multirow{2}{*}{\begin{tabular}{|l|} 
Influence on drug serum concentration \\
Decrease of quetiapine serum concentration by 80 to $86 \%$ [39-42]
\end{tabular}} & \multirow{2}{*}{$\begin{array}{c}\text { Potential clinical consequence } \\
\text { Loss of efficacy }\end{array}$} \\
\hline \multirow[t]{4}{*}{ Carbamazepine } & +Quetiapine & & \\
\hline & +Trazodone & Decrease of trazodone serum concentration by $24 \%$ and its active metabolite by $40 \%[43,44]$ & \\
\hline & +Zolpidem & Decrease of zolpidem serum concentration by $57 \%$ [45] & \\
\hline & +Aripiprazole & Decrease of aripiprazole serum concentration by 60 to $71 \%$ [46-48] & \\
\hline Bupropion & +Venlafaxine & Increase of venlafaxine serum concentration by more than $250 \%[49,50]$ & \multirow[t]{8}{*}{ Adverse drug reactions } \\
\hline Duloxetine & +Metoprolol & Increase of metoprolol area under the plasma concentration-time curve by $180 \%$ [51] & \\
\hline \multirow[t]{2}{*}{ Fluvoxamine } & +Amitriptyline & Increase of amitriptyline serum concentration [52] & \\
\hline & +Clozapine & $\begin{array}{l}\text { Increase of clozapine serum concentration on average by } 200 \text { to } 300 \% \text {, in some patients } \\
\text { up to } 10 \text {-fold [53-55] }\end{array}$ & \\
\hline \multirow[t]{2}{*}{ Melperone } & +Nortriptyline & Increase of nortriptyline serum concentration by $50 \%$ [34] & \\
\hline & +Venlafaxine & Increase of venlafaxine serum concentration by $52 \%$ [24] & \\
\hline \multirow[t]{2}{*}{ Paroxetine } & +Oxycodone & Increase of oxycodone serum concentration by $200 \%$ [56] & \\
\hline & +Risperidone & Increase of risperidone (+ 9-hydroxyrisperidone) serum concentration by 62 to $180 \%[57,58]$ & \\
\hline
\end{tabular}


authors declare no conflicts of interest as well. The research study did not receive funds or support from any source.

\section{Statement of human rights}

For this type of study formal consent is not required.

\section{Acknowledgments}

\section{None}

\section{References}

1. Cadieux RJ (1989) Drug interactions in the elderly. How multiple drug use increases risk exponentially. Postgrad Med 86: 179-186. [Crossref]

2. Fulton MM, Allen ER (2005) Polypharmacy in the elderly: a literature review. $J \mathrm{Am}$ Acad Nurse Pract 17: 123-132. [Crossref]

3. Mallet L, Spinewine A, Huang A (2007) The challenge of managing drug interactions in elderly people. Lancet 370: 185-191. [Crossref]

4. Hines LE, Murphy JE (2011) Potentially harmful drug-drug interactions in the elderly: a review. Am J Geriatr Pharmacother 9: 364-377. [Crossref]

5. Iuppa CA, Nelson LA, Elliott E, Sommi RW (2013) Adverse drug reactions: a retrospective review of hospitalized patients at a state psychiatric hospital. Hosp Pharm 48: 931-935. [Crossref]

6. Seymour RM, Routledge PA (1998) Important drug-drug interactions in the elderly Drugs Aging 12: 485-494. [Crossref]

7. Gonzalez FJ (1988) The molecular biology of cytochrome P450s. Pharmacol Rev 40: 243-288. [Crossref]

8. Danton AC, Montastruc F, Sommet A, Durrieu G, Bagheri H, et al. (2013) Importance of cytochrome $\mathrm{P} 450$ (CYP450) in adverse drug reactions due to drug-drug interactions: a PharmacoVigilance study in France. Eur J Clin Pharmacol 69: 885-888. [Crossref]

9. Hiemke C, Baumann P, Bergemann N, Conca A, Dietmaier O, et al. (2011) AGNP consensus guidelines for therapeutic drug monitoring in psychiatry: update 2011. Pharmacopsychiatry 44: 195-235 [Crossref]

10. Preskorn S, Werder S (2006) Detrimental antidepressant drug-drug interactions: are they clinically relevant? Neuropsychopharmacology 31: 1605-1612; discussion 1613. [Crossref]

11. Hiemke C, Pfuhlmann B (2012) Interactions and monitoring of antipsychotic drugs. Handb Exp Pharmacol: 241-265. [Crossref]

12. Polasek TM, Lin FP, Miners JO, Doogue MP (2011) Perpetrators of pharmacokinetic drug-drug interactions arising from altered cytochrome P450 activity: a criteria-based assessment. Br J Clin Pharmacol 71: 727-736. [Crossref]

13. Fritz D, Ceschi A, Curkovic I, Huber M, Egbring M, et al. (2012) Comparative evaluation of three clinical decision support systems: prospective screening for medication errors in 100 medical inpatients. Eur J Clin Pharmacol 68: 1209-1219 [Crossref]

14. U.S. Food and Drug Administration. Drug Development and Drug Interactions: Table of Substrates, Inhibitors and Inducers. http://www.fda.gov/Drugs/ DevelopmentApprovalProcess/DevelopmentResources/DrugInteractionsLabeling/ ucm093664.htm. Accessed 19 August 2014.

15. Madhusoodanan S, Velama U, Parmar J, Goia D, Brenner R (2014) A current review of cytochrome P450 interactions of psychotropic drugs. Ann Clin Psychiatry 26: 120138. [Crossref]

16. Wenzel-Seifert K, Brandl R, Hiemke C, Haen E (2014) Influence of concomitan medications on the total clearance and the risk for supra-therapeutic plasma concentrations of Citalopram. A population-based cohort study. Pharmacopsychiatry 47: 239-244. [Crossref]

17. Guo JJ, Wu J, Kelton CM, Jing Y, Fan H, et al. (2012) Exposure to potentially dangerous drug-drug interactions involving antipsychotics. Psychiatr Serv 63: 10801088. [Crossref]

18. Montastruc F, Sommet A, Bondon-Guitton E, Durrieu G, Bui E, et al. (2012) The importance of drug-drug interactions as a cause of adverse drug reactions: a pharmacovigilance study of serotoninergic reuptake inhibitors in France. Eur J Clin Pharmacol 68: 767-775. [Crossref]
19. McLean AJ, Le Couteur DG (2004) Aging biology and geriatric clinical pharmacology. Pharmacol Rev 56: 163-184. [Crossref]

20. Turnheim K (2003) When drug therapy gets old: pharmacokinetics and pharmacodynamics in the elderly. Exp Gerontol 38: 843-853. [Crossref]

21. Salive ME (2013) Multimorbidity in older adults. Epidemiol Rev 35: 75-83. [Crossref]

22. Sharifi H, Hasanloei MA, Mahmoudi J (2014) Polypharmacy-induced drug-drug interactions; threats to patient safety. Drug Res (Stuttg) 64: 633-637. [Crossref]

23. Haen $\mathrm{E}$ (2011) Therapeutic drug monitoring in pharmacovigilance and pharmacotherapy safety. Pharmacopsychiatry 44: 254-258. [Crossref]

24. Grözinger M, Dragicevic A, Hiemke C, Shams M, Müller MJ, et al. (2003) Melperone is an inhibitor of the CYP2D6 catalyzed O-demethylation of venlafaxine. Pharmacopsychiatry 36: 3-6. [Crossref]

25. Mannheimer B, von Bahr C, Pettersson H, Eliasson E (2008) Impact of multiple inhibitors or substrates of cytochrome P450 2D6 on plasma risperidone levels in patients on polypharmacy. Ther Drug Monit 30: 565-569. [Crossref]

26. Wójcikowski J, Pichard-Garcia L, Maurel P, Daniel WA (2002) Perazine as a poten inhibitor of human CYP1A2 but not CYP3A4. Pol J Pharmacol 54: 407-410. [Crossref]

27. Schaller G, Jacobi A, Rotter A, Kornhuber J, Hillemacher T (2009) Perazine elevates clozapine serum levels by inhibiting hepatic metabolism. Prog Neuropsychopharmacol Biol Psychiatry 33: 908-909. [Crossref]

28. Fischer M, Unterecker S, Deckert J, Pfuhlmann B (2013) Elevated clozapine serum levels in combination with perazine. Psychopharmacology (Berl) 226: 623-625. [Crossref]

29. Flockhart DA (2007) Drug Interactions: Cytochrome P450 Drug Interaction Table Indiana University School of Medicine. http://medicine.iupui.edu/clinpharm/ddis/ clinical-table/. Accessed 19 August 2014

30. Haueis P, Greil W, Huber M, Grohmann R, Kullak-Ublick GA, et al. (2011) Evaluation of drug interactions in a large sample of psychiatric inpatients: a data interface for mass analysis with clinical decision support software. Clin Pharmacol Ther 90: 588-596. [Crossref]

31. Kerr KP, Mate KE, Magin PJ, Marley J, Stocks NP, et al. (2014) The prevalence of co-prescription of clinically relevant CYP enzyme inhibitor and substrate drugs in community-dwelling elderly Australians. J Clin Pharm Ther 39: 383-389. [Crossref]

32. Adson DE, Crow SJ, Meller WH, Magraw RM (1998) Potential drug-drug interactions on a tertiary-care hospital consultation-liaison psychiatry service. Psychosomatics 39: 360-365. [Crossref]

33. Doan J, Zakrzewski-Jakubiak H, Roy J, Turgeon J, Tannenbaum C (2013) Prevalence and risk of potential cytochrome P450-mediated drug-drug interactions in older hospitalized patients with polypharmacy. Ann Pharmacother 47: 324-332. [Crossref]

34. Hefner G, Geschke K, Hiemke C (2014) Severe adverse drug events under combination of nortriptyline and melperone due to pharmacokinetic interaction. J Clin Psychopharmacol 34: 394-396. [Crossref]

35. Preskorn SH, Shah R, Neff M, Golbeck AL, Choi J (2007) The potential for clinically significant drug-drug interactions involving the CYP 2D6 system: effects with fluoxetine and paroxetine versus sertraline. J Psychiatr Pract 13: 5-12. [Crossref]

36. Gould TD, Chen G, Manji HK (2002) Mood stabilizer psychopharmacology. Clin Neurosci Res 2: 193-212. [Crossref]

37. De Winter S, Meersseman W, Verelst S, Willems L, Spriet I (2013) Drug-related admissions due to interaction with an old drug, lithium. Acta Clin Belg 68: 356-358. [Crossref]

38. Nemeroff CB, Preskorn SH, Devane CL (2007) Antidepressant drug-drug interactions clinical relevance and risk management. CNS Spectr 12 (5 Suppl 7):1-13.

39. Grimm SW, Richtand NM, Winter HR, Stams KR, Reele SB (2006) Effects of cytochrome P450 3A modulators ketoconazole and carbamazepine on quetiapine pharmacokinetics. Br J Clin Pharmacol 61: 58-69. [Crossref]

40. Castberg I, Skogvoll E, Spigset O (2007) Quetiapine and drug interactions: evidence from a routine therapeutic drug monitoring service. J Clin Psychiatry 68: 1540-1545. [Crossref]

41. Wittmann M, Hausner H, Köstlbacher A, Hajak G, Haen E (2010) Individual clearance and therapeutic drug monitoring of quetiapine in clinical practice. Neuro Endocrinol Lett 31: 203-207. [Crossref] 
42. Nickl-Jockschat T, Paulzen M, Schneider F, Grözinger M (2009) Drug interaction can lead to undetectable serum concentrations of quetiapine in the presence of carbamazepine. Clin Neuropharmacol 32: 55. [Crossref]

43. Otani K, Ishida M, Kaneko S, Mihara K, Ohkubo T, et al. (1996) Effects of carbamazepine coadministration on plasma concentrations of trazodone and its active metabolite, m-chlorophenylpiperazine. Ther Drug Monit 18: 164-167. [Crossref]

44. Otani K, Yasui N, Kaneko S, Ohkubo T, Osanai T, et al. (1996) Carbamazepine augmentation therapy in three patients with trazodone-resistant unipolar depression. Int Clin Psychopharmacol 11: 55-57. [Crossref]

45. Vlase L, Popa A, Neag M, Muntean D, Bâldea I, et al. (2011) Pharmacokinetic interaction between zolpidem and carbamazepine in healthy volunteers. $J$ Clin Pharmacol 51: 1233-1236. [Crossref]

46. Nakamura A, Mihara K, Nagai G, Suzuki T, Kondo T (2009) Pharmacokinetic and pharmacodynamic interactions between carbamazepine and aripiprazole in patients with schizophrenia. Ther Drug Monit 31: 575-578. [Crossref]

47. Waade RB, Christensen H, Rudberg I, Refsum H, Hermann M (2009) Influence of comedication on serum concentrations of aripiprazole and dehydroaripiprazole. Ther Drug Monit 31: 233-238. [Crossref]

48. Citrome L, Macher JP, Salazar DE, Mallikaarjun S, Boulton DW (2007) Pharmacokinetics of aripiprazole and concomitant carbamazepine. $J$ Clin Psychopharmacol 27: 279-283. [Crossref]

49. Paslakis G, Gilles M, Deuschle M (2010) Clinically relevant pharmacokinetic interaction between venlafaxine and bupropion: a case series. J Clin Psychopharmacol 30: 473-474. [Crossref]

50. Kennedy SH, McCann SM, Masellis M, McIntyre RS, Raskin J, et al. (2002) Combining bupropion SR with venlafaxine, paroxetine, or fluoxetine: a preliminary report on pharmacokinetic, therapeutic, and sexual dysfunction effects. $J$ Clin Psychiatry 63: 181-186. [Crossref]

51. Preskorn SH, Greenblatt DJ, Flockhart D, Luo Y, Perloff ES, et al. (2007) Comparison of duloxetine, escitalopram, and sertraline effects on cytochrome P450 2D6 function in healthy volunteers. J Clin Psychopharmacol 27: 28-34. [Crossref]

52. Vandel S, Bertschy G, Baumann P, Bouquet S, Bonin B, et al. (1995) Fluvoxamine and fluoxetine: interaction studies with amitriptyline, clomipramine and neuroleptics in phenotyped patients. Pharmacol Res 31: 347-353. [Crossref]

53. Szegedi A, Anghelescu I, Wiesner J, Schlegel S, Weigmann H, et al. (1999) Addition of low-dose fluvoxamine to low-dose clozapine monotherapy in schizophrenia: drug monitoring and tolerability data from a prospective clinical trial. Pharmacopsychiatry 32: 148-153. [Crossref]

54. Koponen HJ, Leinonen E, Lepola U (1996) Fluvoxamine increases the clozapine serum levels significantly. Eur Neuropsychopharmacol 6: 69-71. [Crossref]

55. Olesen OV, Starup G, Linnet K (1996) [Serious drug interaction between clozapineLeponex and fluvoxamine-Fevarin]. Ugeskr Laeger 158: 6931-6932. [Crossref]

56. Grönlund J, Saari TI, Hagelberg NM, Neuvonen PJ, Laine K, et al. (2011) Effect of inhibition of cytochrome P450 enzymes 2D6 and 3A4 on the pharmacokinetics of intravenous oxycodone: a randomized, three-phase, crossover, placebo-controlled study. Clin Drug Investig 31: 143-153. [Crossref]

57. Spina E, Avenoso A, Facciolà G, Scordo MG, Ancione M, et al. (2001) Plasma concentrations of risperidone and 9-hydroxyrisperidone during combined treatment with paroxetine. Ther Drug Monit 23: 223-227. [Crossref]

58. Saito M, Yasui-Furukori N, Nakagami T, Furukori H, Kaneko S (2005) Dosedependent interaction of paroxetine with risperidone in schizophrenic patients. J Clin Psychopharmacol 25: 527-532. [Crossref]

59. Lertxundi U, Domingo-Echaburu S, Hernandez R, Peral J, Medrano J (2013) Expertbased drug lists to measure anticholinergic burden: similar names, different results. Psychogeriatrics 13: 17-24. [Crossref]

60. English BA, Dortch M, Ereshefsky L, Jhee S (2012) Clinically significant psychotropic drug-drug interactions in the primary care setting. Curr Psychiatry Rep 14: 376-390. [Crossref]

Copyright: (C2015 Hefner G. This is an open-access article distributed under the terms of the Creative Commons Attribution License, which permits unrestricted use, distribution, and reproduction in any medium, provided the original author and source are credited. 